\title{
Monitoring and Modeling of the Reaction Dynamics in the Valine/Leucine Synthesis Pathway in Corynebacterium glutamicum
}

\author{
Jørgen Barsett Magnus, ${ }^{\dagger}$ Daniel Hollwedel, ${ }^{\dagger}$ Marco Oldiges, ${ }^{\dagger}$ and Ralf Takors ${ }^{*}, \dagger$,
}

Forschungszentrum Jülich, Institute of Biotechnology 2, D-52425 Jülich, Germany, and Degussa AG, Feed Additives, Kantstr. 2, 33790 Halle/Westfalen, Germany

\begin{abstract}
The intracellular concentrations of the valine and leucine pathway intermediates in a Corynebacterium glutamicum strain were measured during a transient state. The data were obtained by performing a glucose stimulus-response experiment with the use of a rapid sampling device and advanced mass spectrometry. The glucose stimulus resulted in a 3-fold increase in the intracellular pyruvate concentration within less than a second, demonstrating the very fast interactions in metabolic networks. The samples were taken at subsecond intervals for a time period of $25 \mathrm{~s}$. The time courses of the metabolite concentrations formed the experimental basis of a mathematical model simulating the fluxes and concentrations in the valine/leucine pathway. The implementation of a model selection criterion based on the second law of thermodynamics is demonstrated to be essential for the identification of realistic and unique models. Large differences between the enzyme properties determined in vitro and those determined in vivo by the model were observed with the in vivo maximal rates being almost an order of magnitude larger than the in vitro maximal rates. The transamination of ketoisovalerate (KIV) to valine is carried out mainly by the transaminase B enzyme, with the transaminase $\mathrm{C}$ enzyme playing a minor role. The availability of the cofactors NADP and NADPH only has modest influence on the flux through the valine pathway, while the influence of NAD and NADH on the flux through the leucine pathway is negligible.
\end{abstract}

\section{Introduction}

Corynebacterium glutamicum is an aerobic gram-positive bacterium widely used for the industrial production of amino acids, especially L-glutamate and L-lysine $(1,2)$. Its metabolism has, therefore, been the subject of extensive research (3), and its complete genome has been sequenced (4). In addition to L-glutamate and L-lysine, L-valine also represents a commercially interesting product with applications in the cosmetic and pharmaceutical industry. The annual world production of L-valine in 2001 was about 500 tons (5), with L-valine market prices above 30 euros $/ \mathrm{kg}$, depending on the intended use.

Mathematical modeling is required to analyze and gain a systemic understanding of the complex reaction networks of metabolic systems $(6,7)$. During the past decade, several kinetic models of in vivo metabolic networks describing the metabolite dynamics at the enzyme level have been developed. These studies include the penicillin pathway in Penicillium chrysogenum (8), the glycolysis and the pentose phosphate pathway in Saccharomyces cerevisiae $(9,10)$, the L-lysine pathway in Corynebacterium glutamicum (11), the central carbon metabolism in Escherichia coli (12), and many others (13). The enthusiasm for metabolic network models results not only from their ability to provide insight into the biology of cells, but also from their applicability within the area of metabolic engineering (7). An adequate kinetic model can be used to analyze the control hierarchy in the reaction system at the enzyme level

* To whom correspondence should be addressed. E-mail: ralf.takors@ degussa.com.

${ }^{\dagger}$ Institute of Biotechnology.

$\doteqdot$ Degussa AG. and can also give quantitative predictions of the change in fluxes and concentrations following a change in an enzyme activity. It should be noted that kinetic models, such as the ones mentioned above, model the metabolism based on the enzyme properties at the investigated state of the cells. The regulatory network of gene transcription, which decides the enzyme concentrations in the cell, is in general not included in the models. The modeling of such networks is a separate topic in metabolic modeling.

A model-based analysis is also an appropriate way to gain an understanding of the in vivo properties of enzymes. Many enzymes have been analyzed in vitro, but these data cannot be assumed to be valid for the in vivo conditions $(14,15)$ because they are normally measured at different $\mathrm{pH}$, different ion concentrations, and without the influence of the many other compounds present in the cytosol. Kinetic modeling can be seen as a complex in vivo enzyme study, where many enzymes are investigated simultaneously and where their function as parts of a reaction system is analyzed

In this article we present a kinetic model of the valine and leucine synthesis pathways in a recombinant Corynebacterium glutamicum L-valine production strain. The metabolism is analyzed at the enzyme level so effects resulting from gene transcription were not included. All available information on the allosteric regulation of the pathways was incorporated into the model, and thermodynamic constraints were set as part of the model identification procedure. The intracellular concentration measurements used for model identification were obtained from a glucose stimulus -response experiment.

The kinetic rate equations in the presented model are defined using linlog kinetics, as described by Visser and Heijnen (19), 
rather than the more common mechanistically derived equations used for example in the models mentioned above. The linlog kinetic equations are based only on the stoichiometry and the allosteric regulation of the enzyme, so the information about the order at which the substrates and products bind to and leave from the enzyme is lost. However, it was demonstrated that this type of kinetics was able to describe the dynamics of metabolic pathways well and that it was also suitable for design (20). An advantage of the linlog approach is that fewer parameters are required in the model and that the parameters are easy to interpret. Hatzimanikatis $(16-18)$ has suggested a similar kinetic framework called "log-linear kinetics". Here we shall use the format published by Visser and Heijnen (19).

A stimulus-response experiment, often referred to as a pulse experiment $(21-23)$, is a technique which provides data particularly useful for the identification of kinetic models (24). The concentration of an extracellular metabolite, typically glucose, is rapidly increased in the culture, and the response in the cells is measured by collecting samples using a rapid sampling technique, with immediate quenching of the metabolism and subsequent extraction and quantification of the intracellular metabolite concentrations. In this way, the metabolism in the cell is shifted away from its steady state, and time series of the intracellular metabolite concentrations during the transient state are obtained. The quality and usefulness of the data depends on the state of the bacterial culture at the time of the glucose addition and, thus, on the fermentation preceding the experiment. In the presented work, special care has been taken to provide a good experimental basis for the model by measuring the concentrations of all pathway intermediates at subsecond intervals and by carefully designing the experiment to yield the optimal data set.

The aim of the study is to establish a mathematical model of the reaction kinetics in the valine/leucine pathway, as well as developing general methods for kinetic modeling based on stimulus - response experiments. The investigated pathway is particularly suitable for this type of investigation, because it can be expected that the glucose stimulus will have a strong effect on the valine/leucine pathway. Glucose is taken up by the phosphotransferase system, which converts one molecule of phosphoenolpyruvate to pyruvate for every glucose molecule that passes the membrane. The glucose stimulus will, therefore, have a direct effect on the pyruvate concentration. Because the valine/leucine pathway starts with two pyruvate molecules condensing to form one acetolactate molecule, this reaction should be particularly sensitive to changes in the pyruvate concentration and, thus, to the glucose stimulus.

\section{Materials and Methods}

Strain and Cultivation. The recombinant L-valine production

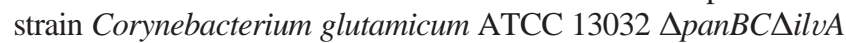
pJC1ilvBNCD (25) was used as a model organism. The strain is isoleucine auxotroph due to the deletion of the threonine dehydratase gene $i l v A$ and pantothenate auxotroph due to the deletion of the panBC genes. The genes corresponding to the first three enzymes in the valine pathway, acetohydroxyacid synthase $(i l v B N)$, acetohydroxyacid isomerase $(i l v C)$, and dihydroxyacid dehydratase $(i l v D)$, are overexpressed on a plasmid to increase valine production. A kanamycine resistance gene on the plasmid applies the necessary selection pressure to avoid loss of plasmid during the fermentation.

The strain was grown in batch fermentation mode in a $20 \mathrm{~L}$ bioreactor (Infors ATGU 503, Basel, Switzerland) with a working volume of $7 \mathrm{~L}$ on the mineral medium CGXII (26). Supplementary trace elements were added according to WeusterBotz et al. (27). In addition, the medium contained $0.24 \mathrm{mg} / \mathrm{L}$ pantothenic acid, $25 \mathrm{mg} / \mathrm{L}$ kanamycinsulfate, and $0.144 \mathrm{~g} / \mathrm{L}$ isoleucine. The correlation between growth and isoleucine consumption was established in previous fermentations with this strain. Thus, isoleucine depletion could be avoided by injecting further isoleucine at three different time points according to the biomass in the fermenter. The culture was, therefore, never at isoleucine limitation.

Glucose concentration in the fermenter was measured with an Accutrend sensor (Roche Diagnostics, Germany). The airflow was kept at $2 \mathrm{~L} / \mathrm{min}$, and the $\mathrm{pH}$ was controlled at 7.6 by the addition of $25 \%$ ammonia. Small amounts of S289 antifoam (Sigma) were added during the fermentation. Oxygen and carbon dioxide concentrations in the exhaust gas were measured continuously using a Binos100 2 M gas analyzer (Rosemount, Germany). Extracellular concentrations of valine, isoleucine, leucine, and alanine were measured on a reversed-phase HPLC, as described by Brik Ternbach et al. (28).

Glucose Stimulus-Response Experiment. The glucose concentration and the dissolved oxygen in the fermenter $\left(\mathrm{pO}_{2}\right)$ were monitored closely to determine the exact point of glucose depletion, that is, the point where the glucose concentration in the fermenter reaches zero. The glucose stimulus-response experiment was performed $10 \mathrm{~min}$ after the glucose in the fermenter was depleted. The 10-minute time delay was established by testing different fermentation strategies.

A special fermenter apparatus, including an injection device for the glucose solution and a rapid sampling system (29), was used to perform the stimulus-response experiment. A total of $50 \mathrm{~mL}$ of a $500 \mathrm{~g} / \mathrm{L}$ glucose solution was rapidly injected into the fermenter by applying a pressure of 4 bar gauge. The glucose concentration in the fermenter increased from 0 to $3.5 \mathrm{~g} / \mathrm{L}$, which is far above most of the half saturation constants for the pts system reported in the literature $(30-32)$. The $90 \%$ mixing time in the fermenter was $650 \mathrm{~ms}$ (33). A total of 47 samples of the fermenter broth were taken at a rate of 2.3 samples per second. The sampling was started $4 \mathrm{~s}$ before the glucose addition to analyze both the concentrations before the glucose addition as well as the transient concentrations during and after the stimulus. The high frequency of the sampling is necessary to observe the rapid changes in the intracellular metabolite concentrations, which are known to have turnover rates in the subsecond range (34).

A sample volume of $5 \mathrm{~mL}$ was taken for each of the 47 samples. The samples were immediately quenched during the sampling process by mixing them directly with $15 \mathrm{~mL}$ of a $60 \%$ methanol solution at $-50{ }^{\circ} \mathrm{C}$. It has been demonstrated that this quenching method does not lead to any leaking of intracellular metabolites for the Corynebacterium glutamicum 13032 strain (35). However, a recent study concluded that some leaking might occur after all when Corynebacterium glutamicum is quenched with cold methanol (36). A potential leaking problem was dealt with in the model by defining the metabolite concentrations relative to the steady state values measured immediately before the glucose stimulus. It is reasonable to assume that the percentage of intracellular metabolites lost during quenching is equal for all samples throughout the sampling sequence, so the scaled concentrations will be the same regardless of the amount lost. The performance of the model is, therefore, not affected by the possible leaking during quenching.

The biomass concentration in the culture was $15.3 \mathrm{~g} \mathrm{DW} / \mathrm{L}$ at the time of the glucose addition. 
Table 1. Measured Metabolites with Their Parent and Product Ions in MS/MS Mode as Well as the Collision Energy Needed for Fragmentation $^{a}$

\begin{tabular}{lrrr}
\hline & parent ion & product ion & collison energy \\
metabolite & $m / z$ & $m / z$ & eV \\
\hline AcLac & 131 & 87 & 10 \\
AKG & 145 & 101 & 10 \\
Ala & 88 & 88 & 7 \\
DHIV & 133 & 75 & 13 \\
Glut & 146 & 127 & 12 \\
IPM & 175 & 115 & 17 \\
KIC & 129 & 85 & 10 \\
KIV & 115 & 71 & 10 \\
Leu & 130 & 84 & 8 \\
NAD & 662 & 540 & 17 \\
NADP & 742 & 620 & 17 \\
Pyr & 87 & 43 & 10 \\
Val & 116 & 116 & 8
\end{tabular}

${ }^{a}$ The metabolite abbreviations are explained in the Notation.

Cell Disruption and Metabolite Extraction. From the moment of sampling, the temperature of the samples was kept at $-20{ }^{\circ} \mathrm{C}$ or lower throughout the metabolite extraction procedure to avoid any further reactions between the metabolites. After centrifugation, the cells were resuspended in $0.5 \mathrm{~mL}$ of $50 \%$ methanol. Cell disruption was performed by adding $2 \mathrm{~mL}$ of a $0.3 \mathrm{M} \mathrm{KOH}$ solution, leaving the sample for $10 \mathrm{~min}$ and then neutralizing with $97 \%$ acetic acid. The cell debris was removed by centrifugation, and the supernatant was filtered through a 5000 Dalton ultrafiltration unit (Vivascience, Hannover, Germany) to remove any remaining enzymes.

In preliminary experiments, the extraction efficiency of the $\mathrm{KOH}$ extraction method was investigated by performing repetitive extraction cycles. In this way, it was established that, from the total amount of an intracellular metabolite present in the cell, $92 \%$ could be extracted with the $\mathrm{KOH}$ method. A perchloric acid disruption method frequently used in similar investigations (37) could extract $88 \%$ of the amount of the metabolites but led to larger standard deviations in the analytical measurements. The KOH disruption also had the advantage that acid-sensitive metabolites would not be affected by the disruption procedure. The levels of NAD and NADP were equal within measurement error for the two disruption methods, whereas NADH and NADPH could not be quantified with either method.

Chemical Analysis. Quantification of the intracellular metabolite concentrations was achieved by using high-pressure liquid chromatography with subsequent tandem mass spectrometry (HPLC-MS/MS).

For the chromatography part, an Agilent 1100 HPLC system (Agilent Technologies, Germany) was used according to a method developed by Buchholz et al. (37). A triple quadrupole, tandem mass spectrometer with an electrospray ionization source (TSQ Quantum, ThermoFinnigan, Germany) and a sample flow rate of $100 \mu \mathrm{L} / \mathrm{min}$ was used for the quantification. The methodspecific parameters of the mass spectrometer were set according to a method developed for the analysis of the central metabolites and the intermediates in the aromatic amino acid metabolism (38). The parameters specific to the measured substances were determined by optimizing the measured signal as reported in Table 1.

Given the large number of samples and metabolites to be measured, it was desired to measure all metabolites in the same ionization mode to save time. The organic acid metabolites can only be ionized and detected in negative ionization mode, whereas most of the amino acids can be quantified more accurately in positive ionization mode (39). The concentration of the amino acids valine, glutamate, leucine, and alanine were high enough to allow an accurate quantification also in negative ionization mode. Hence, negative ionization was chosen.

The standard addition method (40) was used to relate the measured MS signals to the concentrations in the samples. The sample matrix was spiked with standard solutions of the substances in different concentrations and measured to yield the calibration curve. In this way, the noise from the sample matrix (i.e., all the other substances present in the sample) was included in the calculation of the calibration curve.

A standard deviation of about $10 \%$ in the measurements was determined as part of the preliminary investigations. This includes the errors originating from the sampling as well as the measurements on the HPLC-MS. The standard deviations were calculated by measuring several identical samples.

Standards for KIV, isopropylmalate, and ketoisocaproate were obtained from Aldrich (Germany). Dihydroxyisovalerate was obtained from Synthelor (Nancy, France), and L-valine and L-leucine were obtained from Sigma (Germany). Acetolactate was synthesized chemically according to Leyval et al. (41).

A specific intracellular volume of $2 \mu \mathrm{L} / \mathrm{mg}$ DCW (42) was used to calculate the intracellular concentrations.

Fermentation Strategies. The fermentation and the stimulusresponse experiment must be carefully designed to yield a useful data set. Large changes in the metabolite concentrations are desired to provide a good experimental basis for the fitting of the model parameters and to obtain a wide range of validity of the model. Thus, the following two criteria for the setup of the fermentation were formulated: the physiological state of the culture at the time of the stimulus - response experiment should be chosen such that, (i) the results are readily transferable to the production conditions and (ii) the stimulus has a strong effect on the intracellular pools resulting in large deflections in the concentrations.

Criterion (ii) ensures that an information-rich data set is obtained. It should, however, be noted that very large changes might conflict with the kinetic format of the model, depending on how flexible the chosen format is. Visser and Heijnen (19) demonstrated that the linlog kinetics used in this study will give good approximations to a mechanistic model for concentration changes up to a factor 20 . The concentration changes obtained in our stimulus-response experiment were all less than a factor of 4.

The biomass specific valine excretion rate of this strain is at its highest during the exponential growth phase, so according to criterion (i), we want our investigation to be relevant to this state. However, the cells must be limited in their glucose supply immediately before the glucose addition to ensure sufficient glucose input stimulation, so the exponential growth phase is not the preferred observation state. The glucose concentration must be so low that the pts system responsible for glucose uptake is not saturated with glucose. The pts system is often sensitive to the glucose concentration, with apparent $K_{\mathrm{m}}$ values in the micro-molar range (values of 3 to $10 \mathrm{mM}$ have been reported (32)), so when a batch fermentation is performed, the glucose stimulus can in practice first be performed when the glucose has been depleted. By adding the glucose stimulus just after the exponential growth phase has ended, restricting the limitation phase to an absolute minimum, it can be assumed that the enzyme levels in the cells are similar to the enzyme levels during exponential growth. This strategy is also in agreement with criterion (ii). The high activity of the enzymes in the central metabolism ensures that the effect of the increase in extracellular glucose will propagate rapidly through the reaction network and have a strong influence on the metabolite concentrations. As 
Table 2. Reactions in the Valine and Leucine Pathway and the Inhibitors Included in the Model as Well as the Standard Gibbs Free Energy of Aqueous Reaction at the Biological Standard State $\left(\Delta G_{r}^{\circ}\right)^{a}$

\begin{tabular}{|c|c|c|c|}
\hline enzyme & reaction & inhibitor & $\begin{array}{c}\Delta G_{r}^{\circ o^{\prime}} \\
(\mathrm{kJ} / \mathrm{mol})\end{array}$ \\
\hline AHAS & $2 \mathrm{Pyr}=\mathrm{AcLac}+\mathrm{CO}_{2}$ & Val & -53.4 \\
\hline AHAIR & $\begin{array}{l}\text { AcLac + NADPH }+\mathrm{H}= \\
\text { DHIV + NADP }\end{array}$ & Val & -13.6 \\
\hline DHAD & $\mathrm{DHIV}=\mathrm{KIV}+\mathrm{H}_{2} \mathrm{O}$ & Val & -42.3 \\
\hline BCAAT_ValB & $\mathrm{KIV}+\mathrm{Glut}=\mathrm{Val}+\mathrm{AKG}$ & & 0 \\
\hline BCAAT_ValC & $\mathrm{KIV}+\mathrm{Ala}=\mathrm{Val}+\mathrm{Pyr}$ & & 0 \\
\hline Trans_Val & $\mathrm{Val}=$ Valext & Leu & \\
\hline IPMS & $\mathrm{KIV}+\mathrm{AcCoA}=\mathrm{IPM}+\mathrm{CoA}$ & Leu & -223 \\
\hline IPMDH & $\begin{array}{r}\mathrm{IPM}+\mathrm{NAD}=\mathrm{KIC}+ \\
\mathrm{NADH}+\mathrm{H}+\mathrm{CO}_{2}\end{array}$ & & -37.7 \\
\hline BCAAT_LeuB & $\mathrm{KIC}+$ Glut $=\mathrm{Leu}+\mathrm{AKG}$ & & 0 \\
\hline Trans_Leu & Leu $=$ Leuext & Val & \\
\hline
\end{tabular}

${ }^{a}$ The enzyme and metabolite abbreviations are explained in the Notation.

pointed out earlier, it was expected that the sudden increase of glucose uptake would result in an increase in the pyruvate pool and, thus, positively stimulate the flux into the valine biosynthetic pathway.

\section{Modeling}

Model Definition. The model describes the reaction dynamics in the valine and leucine pathway. Table 2 lists the reactions defining the stoichiometry of the system, and Figure 1 depicts the reaction network. The isopropylmalate isomerase reaction transforming 2-IPM to 3-IPM can be treated as a fast nearequilibrium reaction and is, therefore, omitted in the model. Material balances are set up for each metabolite in the valine and leucine pathway, which leads to a system of differential equations on the form:

$$
\frac{\mathrm{d} \mathbf{x}_{\mathbf{b}}}{\mathrm{d} t}=\mathbf{N} \cdot \mathbf{v}(\mathbf{x} ; \mathbf{p})
$$

where $\mathbf{x}_{\mathbf{b}}$ is the vector of the balanced metabolite concentrations, that is, the dependent variables, and $\mathbf{x}$ is the vector of all metabolite concentrations in the system (the balanced metabo- lites plus the external metabolites, which are the independent variables). $\mathbf{N}$ is the stoichiometric matrix, $\mathbf{v}$ is the vector of reaction rate equations, and $\mathbf{p}$ is the parameter vector. The system of differential equations has been written out in the Appendix for easy reference.

Only the intermediates in the valine and leucine pathway are balanced. Other metabolites that take part in the reactions in these pathways such as NADP and glutamate (the independent metabolites in Figure 1) are predefined and are not simulated. For these metabolites, piecewise polynomial splines (43) are defined to represent the time courses of the metabolites by a mathematical function. The Java package JSpline ++ (Excelsior, Novosibirsk, Russia) in combination with the open source package JMat (http://jmat.sourceforge.net) was used to calculate the spline coefficients and visualize the calculated splines. The splines were calculated from the concentration measurements but were smoothed to filter out some of the measurement errors. Figure 2 depicts the splines used for the independent metabolites.

It was not possible to measure the reduced cofactors $\mathrm{NADH}$ and NADPH with reasonable accuracy. To account for these in the model, it was assumed that the sum of NAD and NADH as well as the sum of NADP and NADPH stayed constant during the $25 \mathrm{~s}$ of simulation. In a similar glucose stimulus - response experiment it was observed that this assumption is valid for Saccharomyces cerevisiae during a time span of $120 \mathrm{~s}$ (10). The assumption is further motivated by the fact that Corynebacterium glutamicum lacks the transhydrogenase enzyme. The trajectories of NADH and NADPH were calculated from the trajectories of their oxidized counterparts, where the sum of $\mathrm{NADH}$ and NAD was set equal to 0.8 and the sum of NADPH and NADP was set equal to 0.04 . These sums will give ratios of reduced to oxidized cofactors, which correspond to the ratios reported for Corynebacterium glutamicum in the literature (35, 44-46).

Large errors were also associated with the measurement of $\mathrm{AcCoA}$ and $\mathrm{CoA}$ as a result of the instability of the large CoA molecule. It was, however, clear that these metabolites did not respond much to the glucose stimulus. Rather than including noisy data in the model, which would not have had a significant

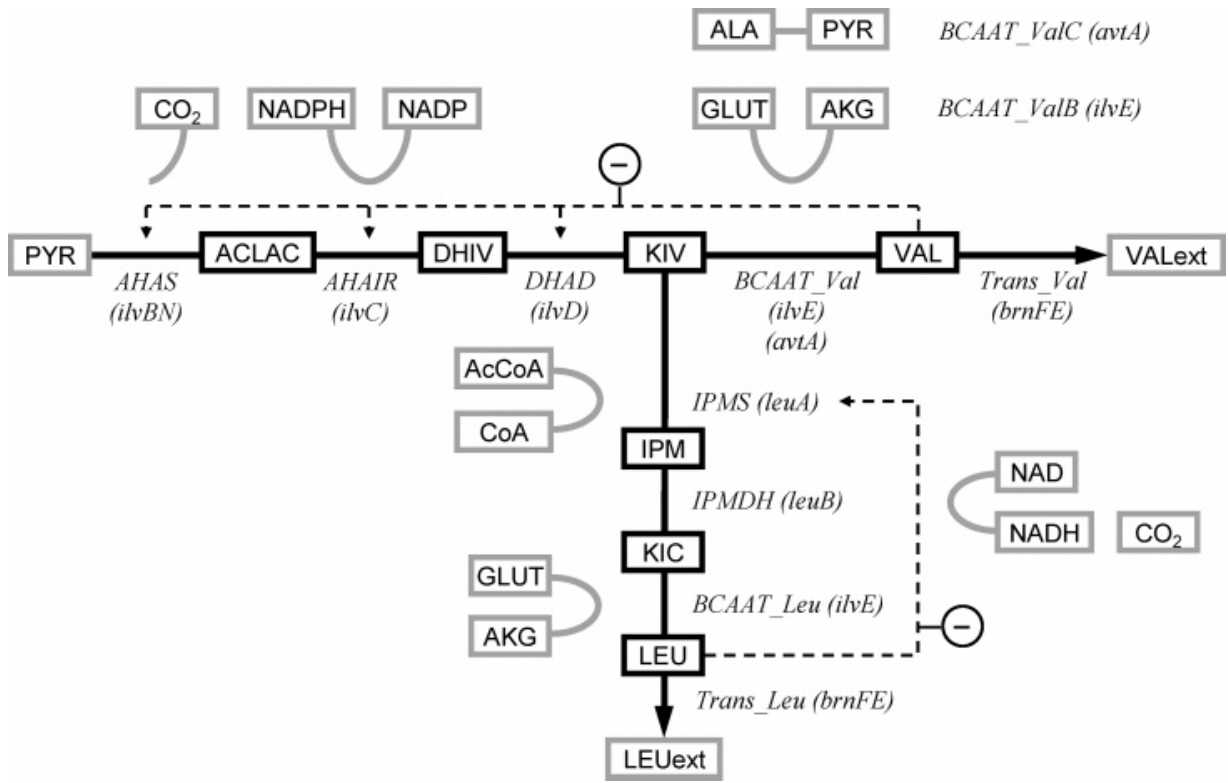

Figure 1. Reaction network of the valine and leucine pathways. The abbreviations are explained in the nomenclature. Valine is synthesized in four reaction steps from pyruvate (PYR). Some of the flux bifurcates toward leucine at the KIV branchpoint. The dependent metabolites are depicted with a black frame and the independent with a gray frame. The broken lines show the allosteric regulation (feedback inhibition) by valine and leucine. In the leucine pathway, IPM represents the sum of the isomers 2-IPM and 3-IPM. Enzyme names are written in italic. 

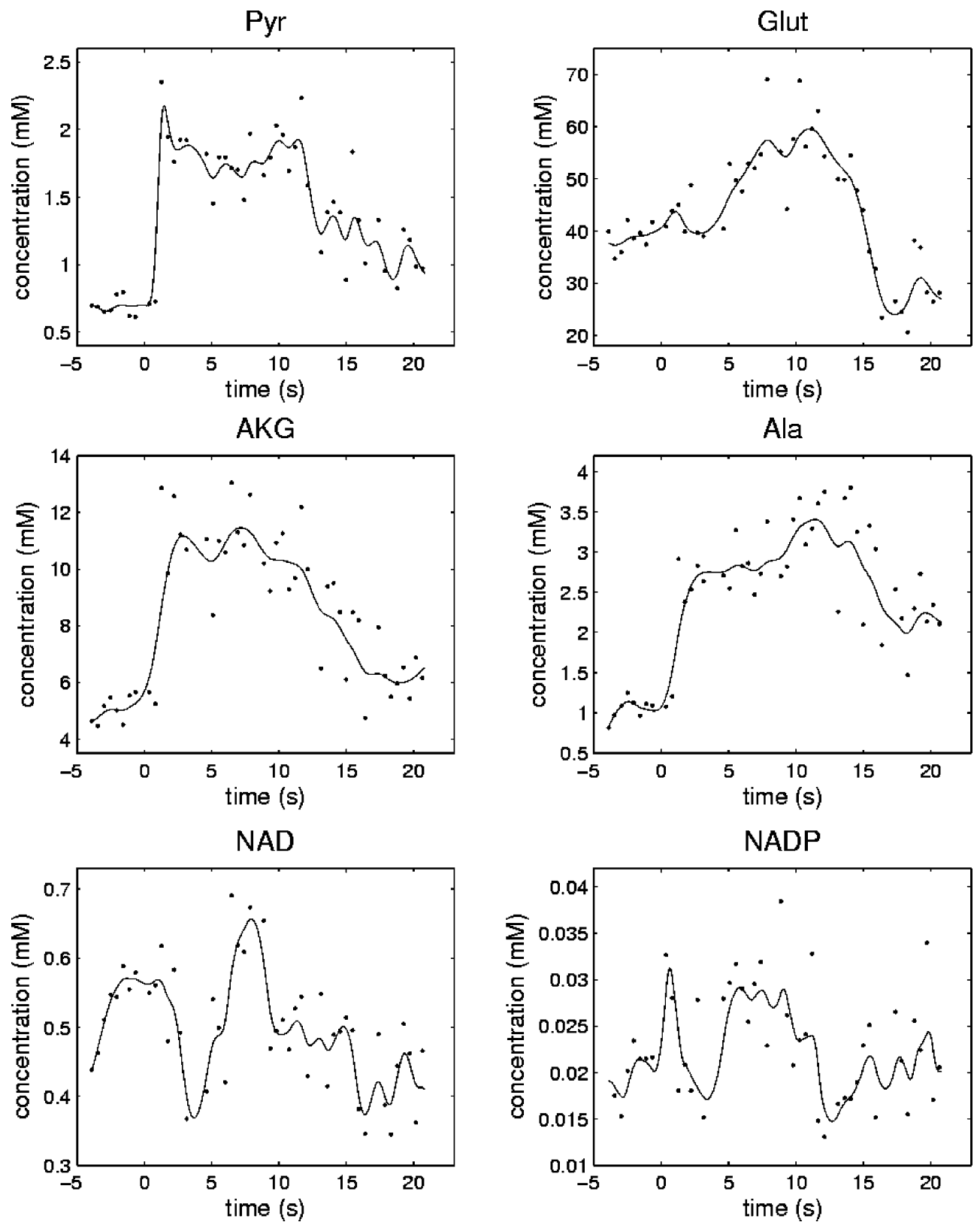

Figure 2. Spline representation of the intracellular concentrations, which were considered external metabolites in the model (lines), and the measurements from which the splines were calculated (dots). Smoothed third-order piecewise polynomial splines were used for all metabolites except for pyruvate, where a second-order pp-spline was used.

influence anyway, these metabolites were excluded from the IPMS rate equation.

Reaction Rate Expressions. The nonmechanistic linlog kinetics (19) was used to define the reaction rate expressions in the model. The formulation of the linlog kinetics was inspired by the idea that the rate of reaction is proportional to the thermodynamic driving force. It is defined as a sum of logarithms of the participating reactants scaled with respect to a reference state. For a reaction $\mathrm{A}+\mathrm{B}=\mathrm{P}+\mathrm{Q}$, allosterically regulated by a modulator $\mathrm{M}$, the rate equation takes the following form:

$$
\begin{aligned}
& v=\frac{e}{e^{0}}\left(1+\epsilon_{\mathrm{A}}^{0} \ln \frac{x_{\mathrm{A}}}{x_{\mathrm{A}}^{0}}+\epsilon_{\mathrm{B}}^{0} \ln \frac{x_{\mathrm{B}}}{x_{\mathrm{B}}^{0}}+\epsilon_{\mathrm{P}}^{0} \ln \frac{x_{\mathrm{P}}}{x_{\mathrm{P}}^{0}}+\epsilon_{\mathrm{Q}}^{0} \ln \frac{x_{\mathrm{Q}}}{x_{\mathrm{Q}}^{0}}+\epsilon_{\mathrm{M}}^{0} \ln \frac{x_{\mathrm{M}}}{x_{\mathrm{M}}^{0}}\right)
\end{aligned}
$$

where $v$ is the reaction rate, $e$ is the enzyme level, $\epsilon_{i}$ is the elasticity of the reaction with respect to metabolite $i$, and $x_{i}$ is the concentration of metabolite $i$. The superscripts ${ }^{0}$ refer to the variable values at the reference state.

The elasticity of a reaction is a property often discussed within the framework of biochemical systems theory and metabolic control analysis (MCA). Some of the more recent reviews on MCA are given by Fell (47), Stephanopoulos et al. (48), and Visser and Heijnen (49). The elasticity is defined as the scaled local partial derivative of the reaction rate with respect to a metabolite:

$$
\epsilon_{i j}=\frac{x_{j}}{v_{i}} \frac{\partial v_{i}}{\partial x_{j}}
$$

An advantage of formulating the linlog kinetic with respect to a reference state, as in eq 2 , is that the parameters equal the enzyme elasticities at the reference state, which makes a direct interpretation of the parameters possible. 
For the parameter fitting of the model, it is useful to apply the formulation:

$$
\frac{e}{e^{0}}\left(v^{0}+a \ln \frac{x_{\mathrm{A}}}{x_{\mathrm{A}}^{0}}+b \ln \frac{x_{\mathrm{B}}}{x_{\mathrm{B}}^{0}}+p \ln \frac{x_{\mathrm{P}}}{x_{\mathrm{P}}^{0}}+q \ln \frac{x_{\mathrm{Q}}}{x_{\mathrm{Q}}^{0}}+m \ln \frac{x_{\mathrm{M}}}{x_{\mathrm{M}}^{0}}\right)
$$

It is most convenient to choose the steady state as the reference state so that the $v^{0}$ and $x^{0}$ parameters are the steadystate flux and concentrations, respectively. The advantage is that information about the steady state can then be included in the model. In a reaction sequence, the $v^{0}$ parameter for each reaction will depend on each other according to the stoichiometry of the reactions. Thus, in our case, we only needed the steadystate excretion rates of valine and leucine to be able to determine the $v^{0}$ parameters for all the reactions. In the general case, the steady state fluxes can be determined by a flux analysis. This leaves only the parameters $a, b, p, q$, and $m$ to be determined through parameter fitting. Notice also that by scaling the metabolite concentrations by the steady-state concentrations, the influence on the model of a possible leaking problem during quenching of the samples has been eliminated as discussed under Materials and Methods.

The enzyme level $e$ is assumed to be constant during the 25 $\mathrm{s}$ that are simulated, so the ratio $e / e^{0}=1$. This is a fundamental assumption in modeling the reaction dynamics at the enzyme level, because one otherwise would have to include gene transcription in the model as well.

Inhibitors were included in the rate equations according to published enzyme studies (41). Valine and leucine are actively transported over the cell membrane by the same protein $(50)$ and are, thus, competing substrates for this protein. This effect can be included in a linlog model by defining leucine as an inhibitor to the valine transport rate and valine as an inhibitor to the leucine transport rate. The inhibitors are listed in Table 2.

Simulation and Parameter Fitting. The program MMT2 $(51,52)$ was used to simulate the concentrations and fluxes and to fit the parameters of the model. The program uses the LSODA integration algorithm (53), an algorithm particularly suitable for stiff systems of ODEs, and a Nelder-Mead Simplex based optimization algorithm called Subplex (54) to fit the parameters. The parameters were fitted to minimize the relative distance between the simulated curves and the measured concentrations. Dynamic sensitivity analysis was performed by using either automatic differentiation or by using finite differences, both methods being implemented in MMT2.

The parameter covariance matrix $\mathbf{M}_{\mathbf{p}}$ is calculated from the dynamic sensitivities and the measurement variances and covariances (55). The Fisher information matrix, FIM, at time point $t_{i}$ is given by:

$$
\mathbf{F I M}_{i}=\mathbf{S}_{i}^{\mathbf{T}} \mathbf{M}_{\mathbf{C}, i}{ }^{-1} \mathbf{S}_{i}
$$

where the superscripts ${ }^{\mathbf{T}}$ and ${ }^{-1}$ signifies matrix transpose and inversion, respectively, $\mathbf{M}_{\mathbf{C}, i}$ is the measurement covariance matrix at time point $t_{i}$, and $\mathbf{S}_{i}$ is the sensitivity matrix of the $\mathrm{m}$ metabolites to the $\mathrm{k}$ parameters at time $t_{i}$ :

$$
\mathbf{S}_{i}=\left[\begin{array}{ccc}
\frac{\mathrm{d} x_{1}}{\mathrm{~d} p_{1}}\left(t_{i}\right) & \cdots & \frac{\mathrm{d} x_{1}}{\mathrm{~d} p_{\mathrm{k}}}\left(t_{i}\right) \\
\vdots & \ddots & \vdots \\
\frac{\mathrm{d} x_{\mathrm{m}}}{\mathrm{d} p_{1}}\left(t_{i}\right) & \cdots & \frac{\mathrm{d} x_{\mathrm{m}}}{\mathrm{d} p_{\mathrm{k}}}\left(t_{i}\right)
\end{array}\right]
$$

Summing the FIM $_{i}$ for all time points gives the total Fisher information matrix, which can be inverted to yield the parameter covariance matrix.

$$
\mathbf{M}_{\mathbf{p}}=\mathbf{F I M}^{-1}
$$

In the study presented here, the intracellular concentrations were observed at 47 different time points.

The model parameters must be independent to calculate the parameter covariance matrix. Linear dependencies between parameters, which may be caused either by linear model dependencies or by significant parameter inaccuracies, for example as a consequence of parameter redundancy, will make the corresponding columns in the sensitivity matrix linearly dependent. This, in turn, leads to a singular Fisher information matrix, in which case the parameter covariance matrix cannot be calculated directly using eqs 5,6 , and 7 .

The parameter covariance matrix provides the standard deviations of the parameters and is, therefore, an important quantity in investigating how the errors in the measurements propagate onto the parameters and to determine the accuracy of the parameters. The correlation matrix is easily calculated from the covariance matrix by using the definition of the correlation coefficient. It is thus possible to analyze the correlation between the parameters.

The FIM can be used to investigate the information richness in a data set (56). In our case, the information richness and, thus, the accuracy of the estimated parameters, depends on the actual course of the time series measurements as well as the accuracy and the number of data points that are taken.

Thermodynamic Constraints. The driving force for chemical reactions is the Gibbs free energy of reaction defined as:

$$
\Delta G_{r}=\Delta G_{r}^{\circ \prime}+R T \ln Q
$$

where $\Delta G_{r}^{\circ \prime}$ is the Gibbs energy of reaction at the biological standard state. The biological standard state is the same as the standard state normally defined for chemical reactions (atmospheric pressure, temperature at $25^{\circ} \mathrm{C}$ ), except that the reference $\mathrm{pH}$ value is 7 . The standard concentrations are $1 \mathrm{M}$ for all reactants except for $\mathrm{H}_{2} \mathrm{O}$, which has a standard concentration of $55.5 \mathrm{M}$ (that of pure water), and for $\mathrm{H}^{+}$and $\mathrm{OH}^{-}$, which have standard concentrations of $10^{-7} \mathrm{M} . R$ is the universal gas constant, $T$ is the temperature in Kelvin, and the reaction quotient, $Q$, is defined as the activities of the products divided by the activities of the substrates. It is assumed here that all activity coefficients equal 1 , so $Q$ is calculated as the concentrations of products divided by the concentrations of substrates. So far, no intracellular metabolite activity measurements have been carried out, so there is no information on the activity coefficients in the literature. Setting these to 1 is probably a reasonable approximation, because the concentrations of the metabolites are relatively low, and the activity coefficients approach 1 as the concentrations approach 0 .

The direction of spontaneous change at constant temperature and pressure is toward lower values of the Gibbs energy, so $\Delta G_{r}$ must always be negative. $\Delta G_{r}$ is a function of the concentrations of the metabolites, so it will change throughout a simulation, however, the following constraint must always apply:

$$
\frac{-\Delta G_{r, i}}{v_{i}} \geq 0
$$

Including this criterion in the model identification process 

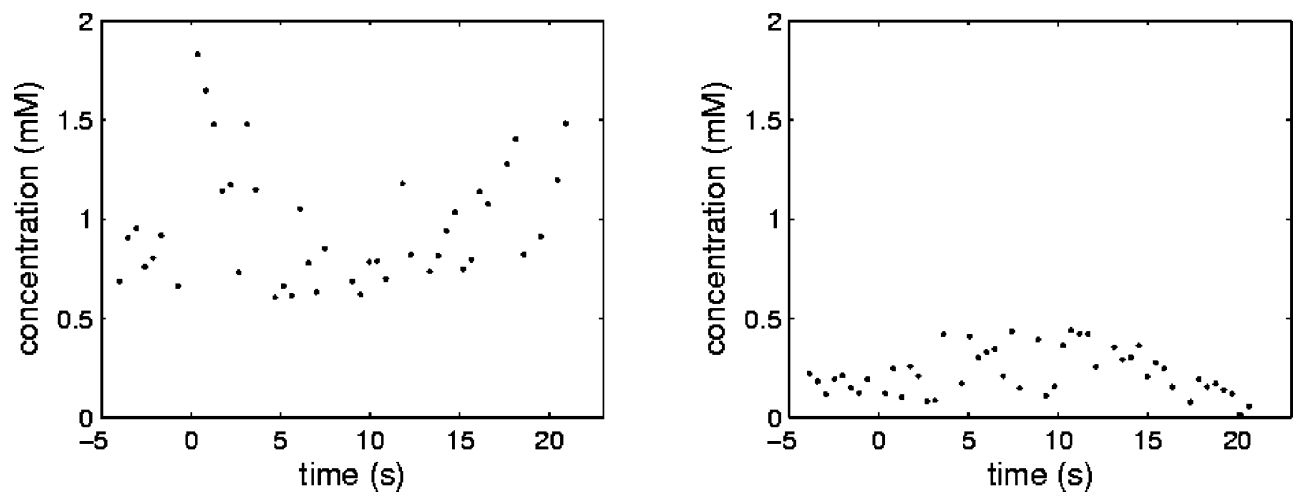

Figure 3. Intracellular pyruvate time course in the two preliminary experiments used to establish the experimental procedure. In experiment 1 (left), batch fermentation was performed and the stimulation was applied directly after glucose depletion. In experiment 2 (right), the stimulation was applied after $3 \mathrm{~h}$ of fed-batch fermentation under glucose limitation.

ensures that all the simulated reaction rates always go in the direction toward lower Gibbs energy, which is an important consideration in establishing realistic models. The constraint applies to all reaction rates $v_{i}$ at all time points, and it, thus, greatly reduces the parameter space in which the optimal parameters are sought.

The Gibbs free energy of formation of the relevant metabolites at the biological standard state was calculated by the group contribution method according to Mavrovouniotis $(57,58)$. The standard Gibbs energy of reaction (reported in Table 2) can then be calculated from the Gibbs energies of formation.

\section{Results and Discussion}

Fermentation. The optimal fermentation strategy with respect to obtaining a useful data set for the modeling was established by performing two preliminary experiments. In experiment 1 , the stimulus was applied immediately after glucose depletion. In experiment 2 , a fed-batch strategy was used to keep the cells at glucose limitation for $3 \mathrm{~h}$ before the stimulus. In this period, glucose was added at a constant rate equal to $1 / 3$ of the uptake rate at exponential growth. The pyruvate time courses of the two preliminary stimulus-response experiments are depicted in Figure 3.

In experiment 1 , there is a clear response in the pyruvate concentration, but large fluctuations during the first $10 \mathrm{~s}$ after the stimulus is seen. These fluctuations could be due to an overlay of effects. When the culture enters the state of glucose limitation, this will result in a perturbation of the metabolite concentrations. The glucose stimulus, added immediately after that, will provide further perturbations, but these will then be superimposed on the oscillations resulting from the glucose depletion. Thus, the obtained data set is not well-defined, and it was, therefore, not used for the model development.

In the second experiment, keeping the cells at glucose limitation for a longer period of time before the glucose addition led to a much lower level of pyruvate and a hardly noticeable response to the glucose stimulus as a result of the lower activity of the enzymes in the glycolysis. The fed-batch strategy was, therefore, conflicting with both criteria set up for the fermentation strategy and was, therefore, ruled out.

In the optimal experiment used for model identification, the 10-minute time delay between glucose depletion and glucose stimulus was long enough to avoid an overlay of effects and short enough to avoid any significant changes in enzyme levels as a result of transcriptional regulation.

The glucose stimulation led to large changes in the intracellular metabolite concentrations within a few seconds and, thus, provided a useful data set for the modeling (see Figures 2, 4, and 5). The concentrations were typically constant before the glucose addition and then increased almost immediately after the stimulus before they settled toward a new steady state after about $15-20 \mathrm{~s}$. An exception to this behavior was shown by $\mathrm{KIV}$, which had a clear decrease in concentration before glucose addition. Similarly, there was an increase in NAD concentration during this period. Most metabolites also had some fluctuations in their concentrations before the stimulus. Fluctuations are known to occur in cellular reaction networks also at steady state (29 and 59). Note that constant concentrations before the stimulus are not a requirement for fitting the model parameters.

Pyruvate, the starting metabolite in the valine/leucine reaction sequence, had a 3-fold increase in concentration within less than a second, demonstrating the fast dynamics of metabolic reaction networks. The strong and definite input signal from pyruvate (as well as from the other independent metabolites, see Figure 2) led to the very clear changes in the dependent metabolites, which is optimal for the analysis of the in vivo enzyme kinetics. The close connection of the valine/leucine pathway to the central metabolism makes it particularly applicable to method development studies in dynamic modeling on the basis of glucose stimulus-response experiments. Other biosynthetic pathways, which are not as closely connected to the central metabolism or originate from more than one precursor, may experience a more complex stimulus effect resulting in stronger oscillations or a buffered, that is, reduced, perturbation as has been observed in the aromatic amino acid pathway (59).

Model. The model simulates the concentrations and fluxes of the valine and leucine pathway during the transient state and also reproduces the steady state concentrations, as well as the steady state excretion rates of $0.23 \mathrm{mM} / \mathrm{s}$ and $0.0026 \mathrm{mM} / \mathrm{s}$ for valine and leucine, respectively (concentrations are given with respect to the intracellular volume). The curves of the seven simulated metabolites were fitted to a total of 316 data points. The spline representations of the six independent metabolites were based on 279 data points, so the total experimental basis of the model was 595 data points. The nine simulated reaction rates contained in total 28 parameters. The concentrations of the metabolites at the reference state used in the model are given in Table 3.

Figures 4 and 5 show the fitting of the model to the data. The input signals from the independent variables (see Figure 2) led to the changes in the simulated concentrations, where especially pyruvate gave a strong input signal directly after the stimulus. Both the period before and after the stimulus could be fitted. The measurements have a standard deviation of about $10 \%$, so the simulated curves need not necessarily go through every measurement point but should represent the general trend 
Table 3. Metabolite Concentrations at the Reference State

\begin{tabular}{cc}
\hline metabolite & $\begin{array}{c}\text { reference concentration } \\
\mathrm{mM}\end{array}$ \\
\hline AcLac & 0.236 \\
AKG & 5.12 \\
Ala & 1.05 \\
DHIV & 0.132 \\
Glut & 38.7 \\
IPM & 0.0227 \\
KIC & 0.0741 \\
KIV & 13.1 \\
Leu & 0.209 \\
NAD & 0.528 \\
NADP & 0.0175 \\
Pyr & 0.689 \\
Val & 29.4
\end{tabular}

of the time course. Most of the metabolite time series could be fitted accurately to the data, including the steep decline and sharp rise of the KIV concentration, but the model was not capable of reproducing the two peaks observed in the DHIV metabolite. These peaks are not observed in the up- and downstream metabolites next to DHIV, namely, AcLac and KIV, whose metabolite dynamics are well-described by the model. It is worth noticing that the KIV concentrations are up to 50 times higher than those of its precursor DHIV. Hence, DHIV pool turnover is much faster than KIV, resulting in high pool sensitivities with respect to the estimated flux dynamics. However, flux estimations are numerically dominated by the fluctuations in the large KIV (and valine) pool, thus giving DHIV dynamics only a minor significance. Mechanistically, DHIV dynamics might have been caused by varying NADP/H ratios, which, as already described, could only be estimated by the experimental approach chosen.

The identified model parameters and their standard deviations are given in Table 4. Five parameters initially included in the
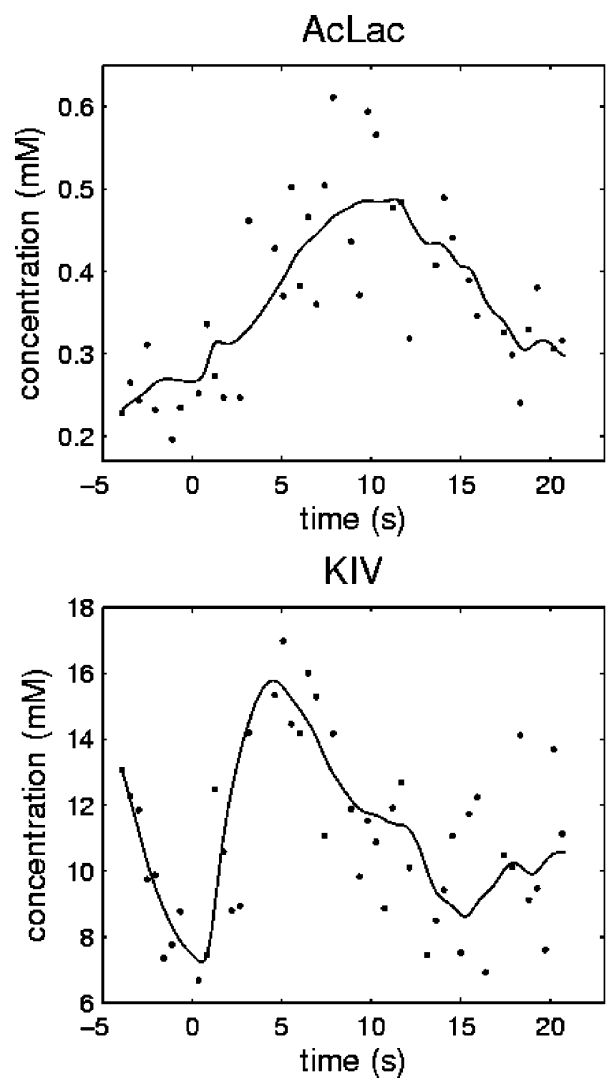

model obtained the value 0 and could be deleted from the model. The parameters corresponding to NAD and NADH in the isopropylmalate dehydrogenase (IPMDH) reaction were among the parameters that could be deleted, which demonstrates that although NAD and NADH are reaction partners of the IPMDH reaction, they did not have significant influence on the reaction rate in the modeled concentration range.

The large changes in the simulated fluxes demonstrate the highly dynamic behavior of metabolic networks (Figure 6). Most notable is the rapid increase in the acetohydroxy acid synthase (AHAS) rate, the starting reaction in the sequence, which increases to a value of almost $6 \mathrm{mM} / \mathrm{s}$ directly after glucose addition. This is about 25 times the steady state flux, which shows the strong stimulus of the valine pathway that was achieved with the established experimental strategy. The enzymes in the reaction system respond very quickly to the changes in the metabolite concentrations, with immediate changes in the reaction rates. This demonstrates the flexibility and responsiveness of an intracellular reaction network, which is necessary to avoid very large changes in metabolite levels. Such changes could be damaging for the cell. Substrate saturation of the enzymes is not present to a significant degree, as this would prevent the rapid changes in reaction rate. Note also that the cell manages to control its fluxes despite the high level of the inhibitor valine present in the cell. The enzymes AHAS and AHAIR are strongly inhibited at valine concentrations of more than $20 \mathrm{mM}$ (41), but a complete inhibition does not take place, as has been observed for AHAS (60) for which a $43 \%$ activity remains at saturating valine concentrations.

The simulation of the intracellular fluxes further demonstrates the difference between the in vivo and in vitro properties of the enzymes. Leyval et al. (41) determined the maximal rate of the AHAS enzyme in Corynebacterium glutamicum ATCC
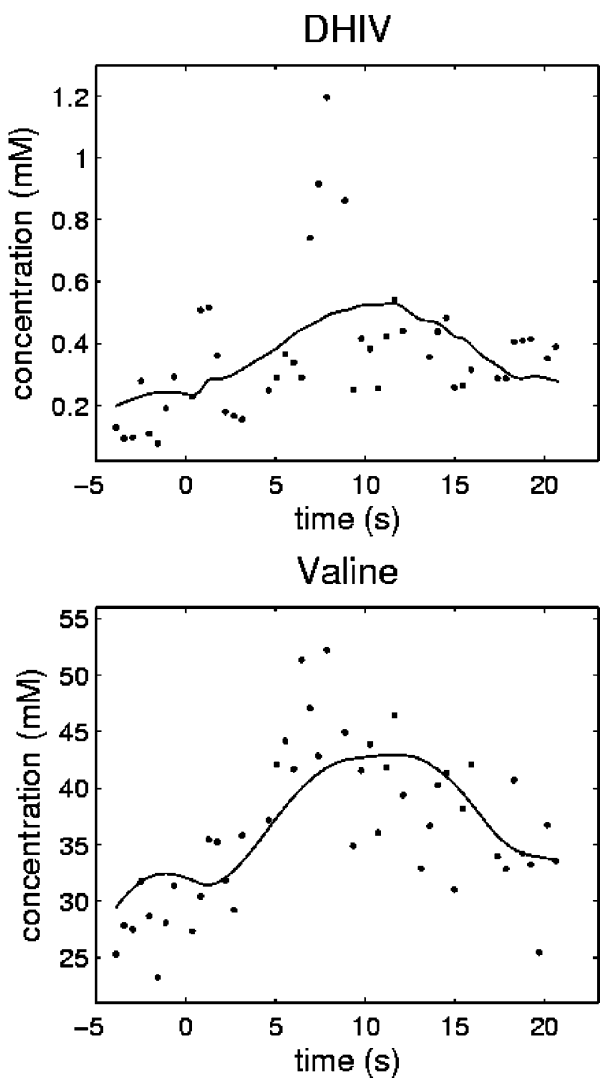

Figure 4. Simulation of the intracellular metabolites in the valine pathway (lines), and the measurements that were used to fit the parameters in the model (dots). 
IPM

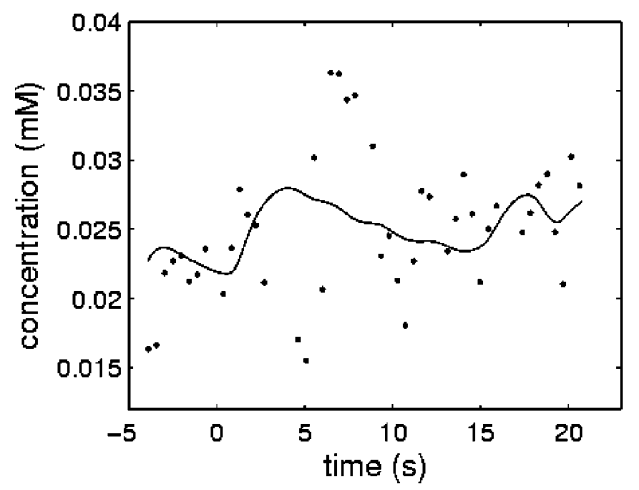

Leu

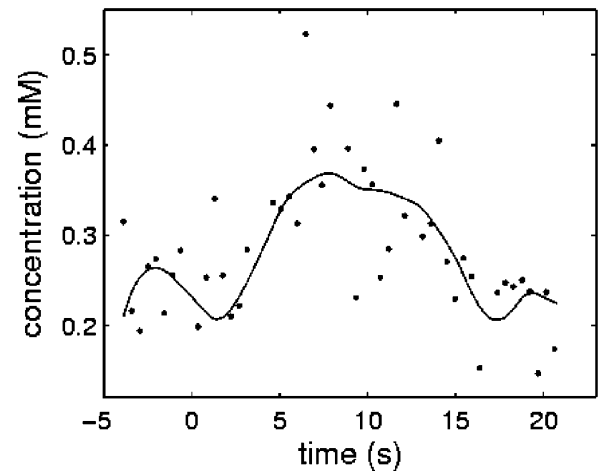

$\mathrm{KIC}$

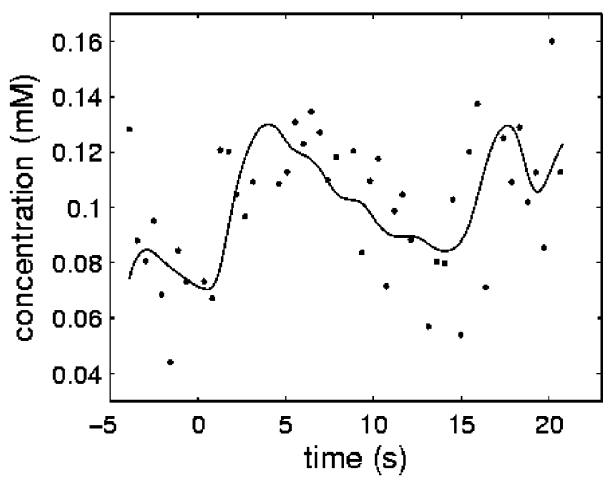

Figure 5. Simulation of the intracellular metabolites in the leucine pathway (lines), and the measurements that were used to fit the parameters in the model (dots).

Table 4. Values of the Parameters Corresponding to the Different Reactants and Effectors in the Respective Reactions ${ }^{a}$

\begin{tabular}{|c|c|c|c|c|}
\hline enzyme & metabolite & $\begin{array}{c}\text { parameter } \\
\text { value }(\mathrm{mM})\end{array}$ & $\begin{array}{c}\text { standard } \\
\text { deviation } \\
(\mathrm{mM})\end{array}$ & elasticity \\
\hline AHAS & $\begin{array}{l}\text { Pyr } \\
\text { AcLac } \\
\text { Val }\end{array}$ & $\begin{array}{r}6.08 \\
-4.35 \\
-2.83\end{array}$ & $\begin{array}{l}2.4 \\
12 \\
20\end{array}$ & $\begin{array}{r}25.9 \\
-18.5 \\
-12.1\end{array}$ \\
\hline AHAIR & $\begin{array}{l}\text { AcLac } \\
\text { NADPH } \\
\text { DHIV } \\
\text { NADP } \\
\text { Val }\end{array}$ & $\begin{array}{l}34.7 \\
0.00215 \\
-3.31 \\
-2.59 \\
-53.5\end{array}$ & $\begin{array}{l}81 \\
26 \\
66 \\
20 \\
30\end{array}$ & $\begin{array}{c}148 \\
0.00917 \\
-14.1 \\
-11.0 \\
-228\end{array}$ \\
\hline DHAD & $\begin{array}{l}\text { DHIV } \\
\text { KIV } \\
\text { Val }\end{array}$ & $\begin{array}{l}26.1 \\
-0.00319 \\
-62.8\end{array}$ & $\begin{array}{l}9.7 \\
1.8 \\
24\end{array}$ & $\begin{array}{l}111 \\
-0.0136 \\
-267\end{array}$ \\
\hline BCAAT_Val & $\begin{array}{l}\text { KIV } \\
\text { Glut } \\
\text { Ala } \\
\text { AKG }\end{array}$ & $\begin{array}{l}3.82 \\
1.40 \\
0.0283 \\
-0.00275\end{array}$ & $\begin{array}{l}0.62 \\
0.79 \\
1.1 \\
1.3\end{array}$ & $\begin{array}{c}16.4 \\
6.01 \\
0.122 \\
-0.0119\end{array}$ \\
\hline Trans_Val & $\begin{array}{l}\text { Val } \\
\text { Leu }\end{array}$ & $\begin{array}{r}9.99 \\
-3.32\end{array}$ & $\begin{array}{l}3.3 \\
1.5\end{array}$ & $\begin{array}{r}42.5 \\
-14.1\end{array}$ \\
\hline IPMS & $\begin{array}{l}\text { KIV } \\
\text { IPM } \\
\text { Leu }\end{array}$ & $\begin{array}{c}0.220 \\
-0.267 \\
-0.0203\end{array}$ & $\begin{array}{l}0.075 \\
0.17 \\
0.43\end{array}$ & $\begin{array}{c}83.4 \\
-101 \\
-7.70\end{array}$ \\
\hline IPMDH & $\begin{array}{l}\text { IPM } \\
\text { KIC }\end{array}$ & $\begin{array}{r}5.00 \\
-1.87\end{array}$ & $\begin{array}{c}16 \\
6.0\end{array}$ & $\begin{array}{r}1897 \\
-712\end{array}$ \\
\hline BCAAT_Leu & $\begin{array}{l}\text { KIC } \\
\text { Glut } \\
\text { Leu } \\
\text { AKG }\end{array}$ & $\begin{array}{r}0.602 \\
0.692 \\
-0.359 \\
-0.335\end{array}$ & $\begin{array}{l}0.29 \\
0.35 \\
0.50 \\
0.18\end{array}$ & $\begin{array}{r}229 \\
263 \\
-136 \\
-127\end{array}$ \\
\hline Trans_Leu & $\begin{array}{l}\text { Leu } \\
\text { Val }\end{array}$ & $\begin{array}{c}0.150 \\
-0.0608\end{array}$ & $\begin{array}{l}0.42 \\
0.10\end{array}$ & $\begin{array}{r}56.9 \\
-23.1\end{array}$ \\
\hline
\end{tabular}

${ }^{a}$ The parameter standard deviation is also reported as well as the elasticities of the enzymes for the various reactants.

$13032 \triangle i l v A \mathrm{pJC} 1 \mathrm{ilvBNCD}$ in an in vitro experiment. This strain is almost identical to the strain investigated here (see Materials and Methods section), and it can be assumed that the fraction of AHAS of the total protein in the cell is similar in both strains. Leyval et al. found that the maximal rate of AHAS determined in cell extracts diluted 1 to 10 at $\mathrm{pH} 7.4$ is $175 \mathrm{nmol} / \mathrm{min} \mathrm{mg}$ total protein. When a specific intracellular volume of $2 \mathrm{~mL} / \mathrm{g}$ DCW is used (42) and assuming that the dry cell weight is $52 \%$ protein $(61)$, this corresponds to an intracellular maximal rate of $0.76 \mathrm{mM} / \mathrm{s}$. During the transient state, the AHAS reaction reaches a value of almost $6 \mathrm{mM} / \mathrm{s}$, so the enzyme is clearly much more active in the cytosol than in a test tube.

The fast dynamics of the intracellular reactions is further illustrated by the enzyme elasticities listed in Table 4 . The large elasticities obtained by some of the enzymes indicate the high responsiveness toward changes in the metabolite concentrations. The large values are necessary to explain the observed concentrations. Theoretical studies based on mechanistic reaction equations suggest that enzyme elasticities are in general lower than most of the elasticities reported here. It can for example be shown that a uni-uni Michaelis Menten reaction has elasticities equal to or smaller than 1 (62). The large elasticities reported here illustrate that reactions taking place in vivo are more complicated than what can be explained by simple theoretical considerations or in vitro enzyme analysis. Large in vivo elasticities were also observed by Visser et al. (20) in their analysis of the E. coli model reported by Chassagnole et al. (12).

The accuracy of the parameters in metabolic models is an important issue, which has often been neglected in the past. In the presented work, we have made much effort to make the parameters as accurate as possible by designing the stimulusresponse experiment to yield an information-rich data set and by reducing the number of parameters in the model to a minimum. Even so, many of the parameters obtained large standard deviations, as reported in Table 4. This demonstrates 

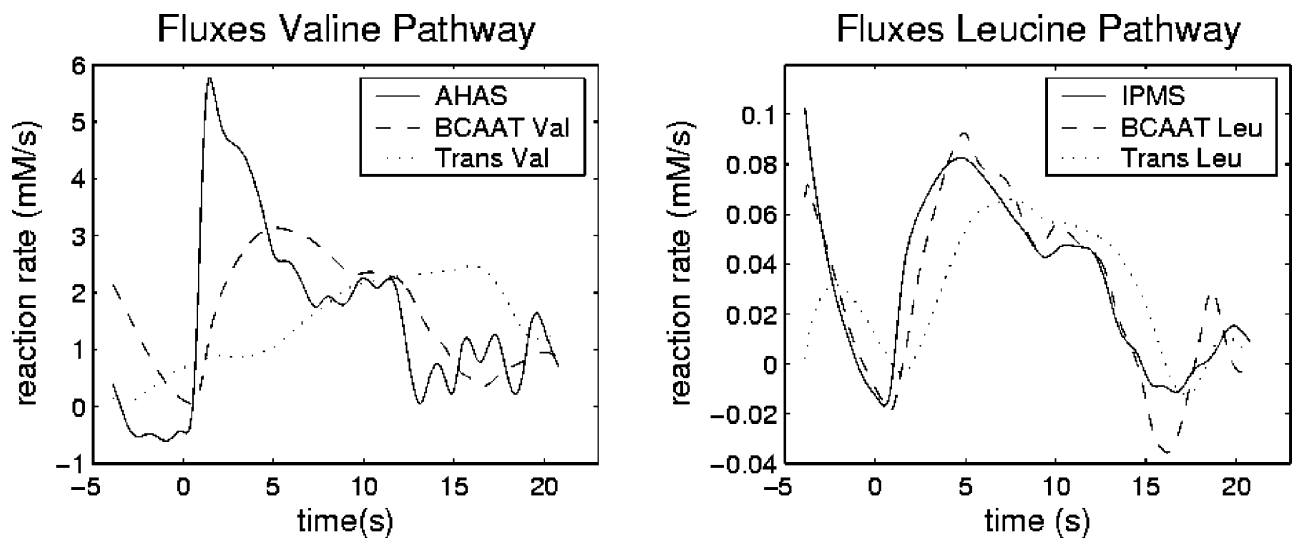

Figure 6. Time course of the simulated fluxes in the valine and leucine pathway. In the valine pathway, the first reaction transforming pyruvate to acetolactate (AHAS) is displayed as well as the transaminase (BCAAT) and the transport (Trans) reaction. The second and third reaction steps (AHAIR and DHAD) are omitted in the plot, as they have very similar time courses to AHAS as a result of the relatively low concentrations in the first three metabolites in this pathway. In the leucine pathway, the time course of the IPMDH reaction is similar to the IPMS reaction.

Table 5. Correlations between the Parameters Corresponding to the Different Reactants and Effectors in the AHAS and AHAIR Reaction ${ }^{a}$

\begin{tabular}{|c|c|c|c|c|c|c|c|c|c|}
\hline & & \multicolumn{3}{|c|}{ AHAS } & \multicolumn{5}{|c|}{ AHAIR } \\
\hline & & Pyr & AcLac & Val & AcLac & NADPH & DHIV & NADP & Val \\
\hline AHAS & $\begin{array}{l}\text { Pyr } \\
\text { AcLac } \\
\text { Val }\end{array}$ & $\begin{array}{c}1 \\
-0.97 \\
0.96\end{array}$ & $\begin{array}{c}1 \\
-0.99\end{array}$ & 1 & & & & & \\
\hline AHAIR & $\begin{array}{l}\text { AcLac } \\
\text { NADPH } \\
\text { DHIV } \\
\text { NADP } \\
\text { Val }\end{array}$ & $\begin{array}{c}0.0017 \\
0.067 \\
-0.019 \\
0.093 \\
0.13\end{array}$ & $\begin{array}{l}0.059 \\
-0.067 \\
-0.036 \\
-0.11 \\
-0.11\end{array}$ & $\begin{array}{r}-0.059 \\
0.055 \\
0.040 \\
0.090 \\
0.10\end{array}$ & $\begin{array}{r}1 \\
0.45 \\
-0.99 \\
0.21 \\
0.55\end{array}$ & $\begin{array}{r}1 \\
-0.48 \\
0.96 \\
0.44\end{array}$ & $\begin{array}{c}1 \\
-0.26 \\
-0.67\end{array}$ & $\begin{array}{l}1 \\
0.34\end{array}$ & 1 \\
\hline
\end{tabular}

${ }^{a}$ Extract of the full correlation matrix; the correlation matrix is symmetric with respect to its main diagonal.
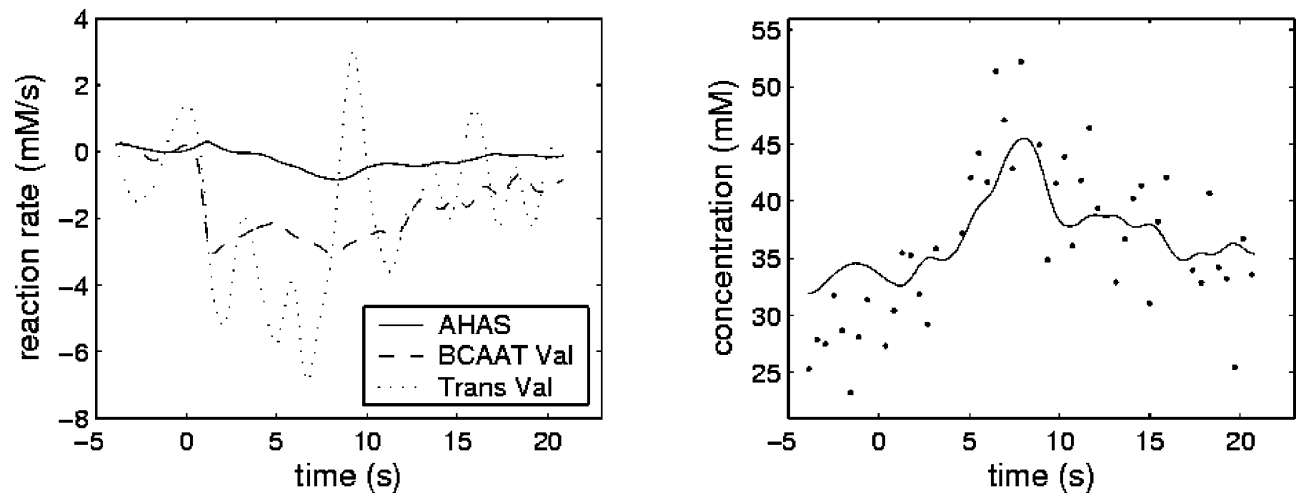

Figure 7. Simulations of a model where the transaminase $\mathrm{C}$ is the dominating enzyme in the transamination reaction. The fluxes (left) comply with the thermodynamic constraint only $41 \%$ of the time during the transient state. The model is, therefore, rejected despite the fact that the simulated concentrations fit the measurements well, as illustrated by the valine simulation (right).

the importance of having a broad data basis for the identification of the model parameters. To improve the accuracy of the parameters further, the accuracy of the intracellular measurements must be improved.

The correlations between the parameters were in general low, with $97 \%$ of the parameter correlations being smaller than 0.9 in absolute value, signifying an independent parameter set. An exception to this is seen in the AHAS reaction, where all three parameters are strongly correlated (see Table 5). The metabolites involved in this reaction, Pyr, AcLac, and Val, all have relatively similar time courses, and because AHAS is the starting reaction in the sequence, this reaction only occurs in one differential equation, namely, the one corresponding to the material balance of AcLac. The parameters, which are the coefficients of the logarithmic terms of the Pyr, AcLac, and Val metabolites, therefore, affect the system in a similar manner and are, thus, highly correlated.
A model of an intracellular reaction network is necessarily a simplification of the real system. The assumption that the cytosol is perfectly mixed for instance, an assumption made in all kinetic models, might not be entirely correct. Other unknown effects affecting the reaction rates may also be present in the cell. The linlog equations are, therefore, only an approximate representation of the true reaction kinetics. Thus, it was not possible to fit the model with a $100 \%$ agreement with the thermodynamic constraint. Some errors might occur as a result of the assumption that the activity coefficients equal 1 , but this probably plays a minor role. The assumption that the sum of NAD and NADH and the sum of NADP and NADPH stay constant also does not contribute significantly to errors, as the model is relatively insensitive toward these cofactors. Even if a full agreement with the thermodynamic constraint could not be achieved, the constraint was still very useful in fitting the 28 parameters. Parameter sets that strongly disagreed with the thermodynamic 
constraint could be rejected, and the constraint, therefore, reduced the parameter search space and made the search for a global optimum easier. In the presented model, the fluxes agree with the constraint in $92 \%$ of the simulated time. This was the best that could be achieved while still obtaining a good fit to the measured concentrations.

Thermodynamic considerations can also shed light on the functionality of the network, as was the case for the transaminase reaction of KIV to valine. Corynebacterium glutamicum possesses both a transaminase B and a transaminase C enzyme (41), so the amino group can be donated either by glutamate or by alanine in this reaction. A model having transaminase $\mathrm{C}$ as the dominating enzyme will inevitably lead to a strong conflict with the thermodynamic constraint. This is illustrated by looking at a model where the transaminase reaction is catalyzed mainly by transaminase $\mathrm{C}$ (Figure 7 ). The fitting of the simulated concentrations to the measured data is just as good in this model as in the final one (compare the fitting of valine here to the fitting of valine given in Figure 4), and the model can also reproduce the steady state concentrations and the steady state fluxes. However, during the transient state, the fluxes agree with the thermodynamic constraint in only $41 \%$ of the simulated time, and the model must, therefore, be rejected. This shows the importance of considering the thermodynamics when developing realistic models. The thermodynamic constraint enabled us to arrive at the conclusion that transaminase B is the dominating enzyme. This confirms the findings of previous investigations based on enzyme studies of this strain $(25,41,63)$.

As we have just seen, several "optimal" parameter sets may exist for a complex kinetic model, that is, there is not always a unique solution when only the fit to the measured data is considered. To identify a unique parameter set, additional constraints or data must be included. In this context, the thermodynamic constraint is an essential tool for the identification of realistic and unique kinetic models.

When including the thermodynamic constraint in the fitting, the same optimal parameter set was always found when starting from different random initial parameters. It can, therefore, be concluded that the identified parameter set is unique and that the model is as realistic as it is possible to achieve with the method used.

An important criterion for the establishment of a useful model is that it is stable. The stability of a model can be investigated by analyzing the Jacobian matrix of the system of ODEs. The Jacobian for the system presented here was fully ranked, so all eigenvalues were nonzero. The system is stable if, and only if, all the eigenvalues of the Jacobian have negative real parts (64). This was the case here, and we can, therefore, conclude that the system will always return to the steady state after a small perturbation in the concentrations. Such small perturbations are known to occur in industrial scale fermentations (65). Furthermore, a conjugate pair of complex eigenvalues was found, signifying that the system is able to oscillate. The ability of real systems to oscillate has been observed experimentally, for example, by Schaefer et al. (29) and by Oldiges et al. (59).

\section{Conclusion}

The presented kinetic model gives a quantitative description of the fluxes and concentrations in the valine/leucine pathway and provides the means for a systemic understanding of the reactions in the pathway. Including the second law of thermodynamics as a criterion in the model development is essential to establish a realistic model. Considering the thermodynamics also provides further insight into the metabolism of the cell.
Enzymes may have very different properties under in vivo and in vitro conditions, thus, a mathematical model is required to understand the in vivo kinetics. The model is suitable for providing the basis of a metabolic control analysis and may, therefore, be an important tool in the rational design of this strain. The analysis of the control hierarchy in the valine and leucine pathways on the basis of the model and the experimental data is a topic for future investigation.

\section{Acknowledgment}

The authors would like to thank Prof. C. Wandrey for providing the excellent working conditions at the Institute of Biotechnology (IBT), Forschungszentrum Jülich. We are also indebted to Dr. L. Eggeling at the IBT for providing the strain and for giving valuable biological input during the development of the model. Furthermore, we would like to thank Dr. H. D. Narres at the Institute of Agrosphere (Forschungszentrum Jülich) for cooperation on the measurements of the intracellular metabolites. Many thanks also to M. D. Haunschild, A. Wahl, and Prof. W. Wiechert at the Department of Simulation, University of Siegen for the development of the MMT2 software and the valuable cooperation on kinetic modeling. The project was funded by the Deutsche Forschungsgemeinschaft DFG Grant TA241/3-2.

\section{Appendix}

System of ordinary differential equations:

$$
\begin{aligned}
& \frac{\mathrm{d} x_{\mathrm{AcLac}}}{\mathrm{d} t}=v_{\mathrm{AHAS}}-v_{\mathrm{AHAIR}} \\
& \frac{\mathrm{d} x_{\text {DHIV }}}{\mathrm{d} t}=v_{\mathrm{AHAIR}}-v_{\mathrm{DHAD}} \\
& \frac{\mathrm{d} x_{\mathrm{KIV}}}{\mathrm{d} t}=v_{\mathrm{DHAD}}-v_{\mathrm{BCAAT} \_ \text {Val }}-v_{\text {IPMS }} \\
& \frac{\mathrm{d} x_{\mathrm{Val}}}{\mathrm{d} t}=v_{\mathrm{BCAAT} \_\mathrm{Val}}-v_{\text {Trans_Val }} \\
& \frac{\mathrm{d} x_{\mathrm{IPM}}}{\mathrm{d} t}=v_{\mathrm{IPMS}}-v_{\mathrm{IPMDH}} \\
& \frac{\mathrm{d} x_{\mathrm{KIC}}}{\mathrm{d} t}=v_{\mathrm{IPMDH}}-v_{\mathrm{BCAAT} \_ \text {Leu }} \\
& \frac{\mathrm{d} x_{\text {Leu }}}{\mathrm{d} t}=v_{\text {BCAAT_Leu }}-v_{\text {Trans_Leu }}
\end{aligned}
$$

The reaction rate equations are set up according to eq 4, with the parameter values found in Table 4. As an example, the AHAS reaction obtains the form:

$$
\begin{aligned}
& v_{\mathrm{AHAS}}= \\
& v_{\mathrm{AHAS}}^{0}+6.08 \ln \left(\frac{x_{\mathrm{Pyr}}}{x_{\mathrm{Pyr}}^{0}}\right)-4.35 \ln \left(\frac{x_{\mathrm{AcLac}}}{x_{\mathrm{AcLac}}^{0}}\right)-2.38 \ln \left(\frac{x_{\mathrm{Val}}}{x_{\mathrm{Val}}^{0}}\right)
\end{aligned}
$$

\section{Notation}

Enzymes

AHAIR acetohydroxy acid isomeroreductase

AHAS acetohydroxy acid synthase

BCAAT_LeuB branched chain amino acid transaminase B (leucine) 
BCAAT_ValB branched chain amino acid transaminase B (valine)

BCAAT_ValC branched chain amino acid transaminase C (valine)

DHAD dihydroxy acid dehydratase

IPMDH isopropylmalate dehydrogenase

IPMS isopropylmalate synthase

Trans_Leu transport (leucine)

Trans_Val transport (valine)

Metabolites

$\begin{array}{ll}\text { AcCoA } & \text { acetyl coenzyme A } \\ \text { AcLac } & \text { acetolactate } \\ \text { AKG } & \alpha \text {-ketoglutarate } \\ \text { Ala } & \text { L-alanine } \\ \text { CoA } & \text { coenzyme A } \\ \text { DHIV } & \text { dihydroxyisovalerate } \\ \text { Glut } & \text { L-glutamate } \\ \text { IPM } & \text { isopropylmalate } \\ \text { KIC } & \text { ketoisocaproate } \\ \text { KIV } & \text { ketoisovalerate } \\ \text { Leu } & \text { L-leucine } \\ \text { NAD } & \text { nicotinamide adenine dinucleotide, oxidized } \\ \text { NADH } & \text { nicotinamide adenine dinucleotide, reduced } \\ \text { NADP } & \text { nicotinamide adenine dinucleotide phosphate, } \\ & \text { oxidized } \\ \text { NADPH } & \text { nicotinamide adenine dinucleotide phosphate, } \\ & \text { reduced } \\ \text { Pyr } & \text { pyruvate } \\ \text { Val } & \text { L-valine }\end{array}$

\section{References and Notes}

(1) Eggeling, L.; Sahm, H. L-glutamate and L-lysine: traditional products with impetuous developments Appl. Microbiol. Biotechnol. 1999, 52, 146-153.

(2) de Graaf, A. A. In Bioreaction Engineering; Schügerl, K., Bellgardt, K. H., Eds.; Springer: Berlin, 2000.

(3) Sahm, H.; Eggeling, L.; de Graaf, A. A. Pathway Analysis and Metabolic Engineering in Corynebacterium glutamicum. Biol. Chem. 2000, 381, 899-910.

(4) Kalinowski, J.; Bathe, B.; Bartels, D.; Bischoff, N.; Bott, M.; Burkovski, A.; Dusch, N.; Eggeling, L.; Eikmanns, B. J.; Gaigalat, L.; Goesmann, A.; Hartmann, M.; Huthmacher, K.; Kraemer, R.; Linke, B.; McHardy, A. C.; Meyer, F.; Möckel, B.; Pfefferle, W.; Pühler, A.; Rey, D. A.; Rueckert, C.; Rupp, O.; Sahm, H.; Wendisch, V. F.; Wiergraebe, I., Tauch, A. The complete Corynebacterium glutamicum ATCC 13032 genome sequence and its impact on the production of L-aspartate derived amino acids and vitamins $J$. Biotechnol. 2003, 104, 5-25.

(5) Eggeling, L.; Pfefferle, W.; Sahm, H. In Basic Biotechnology; Ratledge, C. K. B., Ed.; Cambridge University Press: New York, 2001.

(6) Bailey, J. E. Mathematical modelling and analysis in biochemical engineering: Past accomplishments and future opportunities. Biotechnol. Prog. 1998, 14, 8-20.

(7) Wiechert, W. Modeling and simulation: tools for metabolic engineering. J. Biotechnol. 2002, 94, 37-63.

(8) Pissara, P. D.; Nielsen, J.; Bazin, M. Pathway kinetics and metabolic control analysis of a high-yielding strain of Penicillium chryogenum during fed batch cultivations Pathway kinetics and metabolic control analysis of a high-yielding strain of Penicillium chryogenum during fed batch cultivations. Biotechnol. Bioeng. 1996, 51, 168-176.

(9) Rizzi, M.; Baltes, M.; Theobald, U.; Reuss, M. In vivo analysis of metabolic dynamics in Saccharomyces cerevisiae: II. Mathematical model. Biotechnol. Bioeng. 1997, 55, 592-608.

(10) Vaseghi, S.; Baumeister, A.; Rizzi, M.; Reuss, M. In vivo dynamics of the pentose phosphate pathway in Saccharomyces cerevisiae. Metab. Eng. 1999, 1, 128-140.
(11) Yang, C.; Hua, Q.; Shimizu, K. Development of a kinetic model for L-lysine biosynthesis in Corynebacterium glutamicum and its application to metabolic control analysis. J. Biosci. Bioeng. 1999, $88,393-403$.

(12) Chassagnole, C.; Noisommit-Rizzi, N.; Schmid, J. W.; Mauch, K.; Reuss, M. Dynamic modeling of the Central Carbon Metabolism of Escherichia coli. Biotechnol. Bioeng. 2002, 79, 53-73.

(13) Olivier, B. G.; Snoep, J. L. Web-based kinetic modelling using JWS Online. Bioinformatics 2004, 20, 2143-2144.

(14) Wright, B. E.; Kelly, P. J. Kinetic models of metabolism in intact cells, tissues and organisms. Curr. Top. Cell. Regul. 1981, 19, 103158 .

(15) Teusink, B.; Passarge, J.; Reijenga, C. A.; Esgalhado, E.; van der Weijden, C. C.; Schepper, M.; Walsh, M. C.; Bakker, B. M.; van Dam, K.; Westerhoff, H. V.; Snoep, J. L. Can yeast glycolysis be understood in terms of in vitro kinetics of the constituent enzymes? Testing biochemistry. Eur. J. Biochem. 2000, 267, 5313-5329.

(16) Hatzimanikatis, V.; Floudas, C. A.; Bailey, J. E. Analysis and design of metablic reaction networks via mixed-integer linear optimization AIChE J. 1996, 42, 1277-1292.

(17) Hatzimanikatis, V.; Bailey, J. E. Effects of spatiotemporal variations on metabolic control: approximate analysis using (log) linear kinetic models. Biotechnol. Bioeng. 1997, 54, 91-104.

(18) Hatzimanikatis, V.; Emmerling, M.; Sauer, U.; Bailey, J. E. Application of mathematical tools for metabolic design of microbial ethanol production. Biotechnol. Bioeng. 1998, 58, 154-161.

(19) Visser, D.; Heijnen, J. J. Dynamic simulation and metabolic redesign of a branched pathway using linlog kinetics. Metab. Eng. 2003, 5, 164-176.

(20) Visser, D.; Schmid, J. W.; Mauch, K.; Reuss, M.; Heijnen, J. J. Optimal redesign of primary metabolism in Escherichia coli using linlog kinetics. Metab. Eng. 2004, 6, 378-390.

(21) Theobald, U.; Mailinger, W.; Reuss, M.; Rizzi, M. In vivo analysis of glucose- induced fast changes in yeast adenine nucleotide pool applying a rapid sampling technique. Anal. Biochem. 1993, 214, 3137.

(22) Theobald, U.; Mailinger, W.; Baltes, M.; Rizzi, M.; Reuss, M. In vivo analysis of metabolic dynamics in Saccharomyces cerevisiae. 1. Experimental observations. Biotechol. Bioeng. 1997, 55, 305316.

(23) Weuster-Botz, D. Sampling tube device for monitoring intracellular metabolite dynamics. Anal. Biochem. 1997, 246, 225-233.

(24) Oldiges, M.; Takors, R. Applying metabolic profiling techniques for stimulus-response experiments: chances and pitfalls. Adv. Biochem. Eng. Biotechnol. 2005, 92, 173-196.

(25) Radmacher, E.; Vaitsikova, A.; Burger, U.; Krumbach, K.; Sahm, H.; Eggeling, L. Linking central metabolism with increased pathway flux: L-Valine accumulation by Corynebacterium glutamicum. Appl. Environ. Microbiol. 2002, 65, 2246-2250.

(26) Keilhauer, C.; Eggeling, L.; Sahm, H. Isoleucine synthesis in Corynebacterium glutamicum: molecular analysis of the ilvB-ilvNilvC operon. J. Bacteriol. 1993, 175, 5595-5603.

(27) Weuster-Botz, D.; Kelle, R.; Frantzen, M.; Wandrey, C. Substrate controlled fed-batch production of L-lysine with Corynebacterium glutamicum. Biotechnol. Prog. 1997, 13, 387-393.

(28) Brik Ternbach, M.; Bollman, C.; Wandrey, C.; Takors, R. Application of model discriminating experimental design for modelling and development of a fermentative fed-batch $\mathrm{L}$-valine production process. Biotechnol. Bioeng. 2005, 91, 356-368.

(29) Schaefer, U.; Boos, W.; Takors, R.; Weuster-Botz, D. Automated sampling device for monitoring intracellular metabolite dynamics. Anal. Biochem. 1999, 270, 88-96.

(30) Lengeler, J. W.; Drews, G.; Schlegel, H. G. Biology of Procaryotes; Thieme: Stuttgart, New York, 1999.

(31) Ferenci, T. Adaptation to life at micromolar nutrition levels: the regulation of Escherichia coli glucose transport by endoinduction and cAMP. FEMS Microbiol. Rev. 1996, 18, 301-317.

(32) Postma, P. W.; Lengeler, J. W.; Jacobson, G. R. Phosphoenolpyruvate:carbohydrate phosphotransferase systems of bacteria. Microbiol. Rev. 1993, 57, 543-594.

(33) Bucholz, A.; Hurlebaus, J.; Wandrey, C.; Takors, R. Metabolomics: quantification of intracellular metabolite dynamics. Biomol. Eng. 2002, 19, 5-15. 
(34) de Koning, W.; van Dam, K. A method for the determination of changes of glycolytic metabolites in yeast on a subsecond time scale using extraction at neutral pH. Anal. Biochem. 1992, 204, 118123.

(35) Moritz, B.; Striegel, K.; de Graaf, A. A.; Sahm, H. Kinetic properties of the glucose-6-phosphate and 6-phosphogluconate dehydrogenases from Corynebacterium glutamicum and their application for predicting pentose phosphate pathway flux in vivo. Eur. J. Biochem. 2000, 267, 3442-3452.

(36) Wittmann, C.; Krömer, J. O.; Kiefer, P.; Binz, T.; Heinzle, E. Impact of the cold shock phenomenon on quatification of intracellular metabolites in bacteria. Anal. Biochem. 2004, 327, 135-139.

(37) Buchholz, A.; Takors, R.; Wandrey, C. Quantification of intracellular metabolites in Escherichia coli $\mathrm{K} 12$ using liquid chromatographic-electrospray ionization tandem mass spectrometric techniques. Anal. Biochem. 2001, 295, 129-137.

(38) Oldiges, M. Ph.D. thesis, University of Bonn, 2004.

(39) Piraud, M.; Vianey-Saban, C.; Petritis, K.; Elfakir, C.; Steghens, J. P.; Morla, A.; Bouchu, D. ESI-MS/MS analysis of underivatised amino acids: a new tool for the diagnosis of inherited disorders of amino acid metabolism. Fragmentation study of 79 molecules of biological interest in positive and negative ionisation mode. Rapid Commun. Mass Spectrom. 2003, 17, 1297-1311.

(40) Bader, M. A systematic approach to standard addition methods in instrumental analysis. J. Chem. Educ. 1980, 57, 703-706.

(41) Leyval, D.; Uy, D.; Delaunay, S.; Goergen, J. L.; Engasser, J. M. Characterisation of the enzyme activities involved in the valine biosynthesis pathway in a valine producing strain of Corynebacterium glutamicum. J. Biotechnol. 2003, 104, 241-252.

(42) Gutmann, M.; Hoischen, C.; Krämer, R. Carrier-mediated glutamate secretion by Corynebacterium glutamicum under biotin limitation. Biochim. Biophys. Acta 1992, 1112, 115-123.

(43) de Boor, C. A practical guide to splines; Springer-Verlag: New York, 1978 .

(44) Dominguez, H.; Rollin, H.; Guyonvarch, A.; Guerqzuin-Kern, J. L.; Cocaign-Bousquet, M.; Lindley, N. D. Carbon-flux distribution in the central metabolic pathways of Corynebacterium glutamicum during growth on fructose. Eur. J. Biochem. 1998, 254, 96-102.

(45) Gourdon, P.; Lindley, N. D. Metabolic analysis of glutamate production by Corynebacterium glutamicum. Metab. Eng. 1999, 1, 224-231.

(46) Moritz, B.; Striegel, K.; de Graaf, A. A.; Sahm, H. Changes of pentose phosphate pathway flux in vivo in Corynebacterium glutamicum during leucine-limited batch cultivation as determined from intracellular metabolite concentration measurements. Metab. Eng. 2002, 4, 295-305.

(47) Fell, D. A. Metabolic control analysis: a survey of its theoretical and experimental development. Biochem. J. 1992, 286, 313-330.

(48) Stephanopoulos, G. N.; Aristidou, A. A.; Nielsen, J. Metabolic Engineering, Principles and Methodologies; Academic Press: San Diego, 1998.

(49) Visser, D.; Heijnen, J. J. The mathematics of metabolic control analysis revisited. Metab. Eng. 2002, 4, 114-123.
(50) Kennerknecht, N.; Sahm, H.; Yen, M. R.; Patek, M.; Saier, M. H.; Eggeling, L. Export of L-isoleucine from Corynebacterium glutamicum: a two gene encoded member of a new translocator family. J. Bacteriol. 2002, 184, 3947-3956.

(51) Hurlebaus, J.; Buchholz, A.; Alt, W.; Wiechert, W.; Takors, R. MMT - a pathway modeling tool applied to data from rapid sampling experiments. In Silico Biol. 2002, 2, 467-484.

(52) Haunschild, M. D.; Freisleben, B.; Takors, R.; Wiechert, W. Investigating the dynamic behaviour of biochemical networks using model families. Bioinformatics 2005, 21, 1617-1625.

(53) Hindmarsh, A. C. LSODE and LSODI, two new initial value ordinary differential equation solvers. ACM-SIGNUM Newsl. 1980 , $15,10-11$.

(54) Rowan, T. Ph.D. thesis, University of Texas, 1990

(55) Clifford, A. A. Multivariate error analysis; Applied Science Publishers, Ltd.: Essex, U.K., 1973.

(56) Kresnowati, M. T. A. P.; van Winden, W. A.; Heijnen, J. J. Determination of elasticities, concentration and flux control coefficients from transient metabolite data using linlog kinetics. Metab. Eng. 2005, 7, 142-153.

(57) Mavrovouniotis, M. L. Group contributions for estimating standard Gibbs energies of formation of biochemical compounds in aqueous solution. Biotechnol. Bioeng. 1990, 36, 1070-1082.

(58) Mavrovouniotis, M. L. Estimation of standard Gibbs energy changes of biotransformations. J. Biol. Chem. 1991, 266, 1444014445 .

(59) Oldiges, M.; Kunze, M.; Degenring, D.; Sprenger, G. A.; Takors, R. Stimulation, monitoring and analysis of pathway dynamics by metabolic profiling in the aromatic amino acid pathway. Biotechnol Prog. 2004, 20, 1623-1633.

(60) Elisakova, V.; Patek, M.; Holatko, J.; Nesvera, J.; Leyval, D.; Goergen, J. L.; Delaunay, S. Feedback-resistant acetohydroxy acid synthase increases valine production in Corynebacterium glutamicum. Appl. Environ. Microbiol. 2005, 71, 207-213.

(61) Cocaign-Bousquet, M.; Guyonvarch, A.; Lindley, N. Growth rate dependent modulation of carbon flux through central metabolism and the kinetic consequences for glucose limited chemostat cultures of Corynebacterium glutamicum. Appl. Environ. Microbiol. 1996, $62,429-436$

(62) Kacser, H.; Burns, J. A. The control of flux. Symp. Soc. Exp. Biol. 1973, 27, 65-104.

(63) Eggeling, I.; Cordes, C.; Eggeling, L.; Sahm, H. Regulation of acetohydroxy acid synthase in Corynebacterium glutamicum during fermentation of -ketobutyrate to L-isoleucine. Appl. Microbiol. Biotechnol. 1987, 25, 346-351.

(64) Kondepudi, D.; Prigogine, I. Modern thermodynamics from heat engines to dissipative structures; Wiley: Chichester, 1998.

(65) Mauch, K.; Arnold, S.; Reuss, M. Dynamic sensitivity analysis for metabolic systems. Chem. Eng. Sci. 1997, 52, 2589-2598.

Accepted for publication May 30, 2006.

BP060072F 